\section{Principais causas de internação por condições sensíveis à atenção primária no Brasil: uma análise por faixa etária e região}

\section{The main causes of hospitalization for primary health care sensitive conditions in Brazil: an analysis by age groups and region}

Bárbara Laisa Alves Moura 1

Renata Castro da Cunha 2

Rosana Aquino 3

Maria Guadalupe Medina 4

Eduardo Luís Andrade Mota 5

James Macinko 6

Inês Dourado 7

1-5,7 Programa Integrado de Pesquisa e Cooperação Técnica em Formação e Avaliação da Atenção Básica. Instituto de Saúde Coletiva. Universidade Federal da Bahia. Av. Basílio da Gama, s.n. Campos Universitário - Canela. Salvador, BA, Brasil. CEP: 40.110-040. E-mail: blamoura@hotmail.com

6 Departamento de Saúde Pública. Universidade de New York. EUA.

\begin{abstract}
Objectives: to analyze the main reasons for admission to hospital of patients who could be treated by the Brazilian primary care system (ICSAP) by age group and region between 1999 and 2006.

Methods: a mixed ecological study was carried out of the main three reasons for ICSAP in those aged under 20 years. Secondary data were gathered from the Hospital Information System (SIH-SUS) and the Brazilian Institute of Geography and Statistics' 2001 population census (IBGE).

Results: the three main reasons for ICSAP, in those aged under twenty years, were gastroenteritis, asthma and bacterial pneumonia. There was a reduction in the hospitalization rate for gastroenteritis $(-12.0 \%)$ and asthma (-31.8\%) and an increase of $142.5 \%$ in admissions to hospital for bacterial pneumonia, and these trends took a distinct form for each age group and region.

Conclusions: the description of the trends over time revealed positive changes in the rates of admission to hospital for asthma and infectious gastroenteritis and negative changes in the case of pneumonia. Since these health problems are a high priority for primary health care, these findings show the need to undertake more in-depth analysis and reflect further on the determining factors underlying this pattern of admissions to hospital in the country.
\end{abstract}

Key words Primary health care, Gastroenteritis, Asthma, Pneumonia

\section{Resumo}

Objetivos: analisar as tendências das principais causas de internações hospitalares entre aquelas sensiveis à atenção primária (ICSAP) no Brasil, por faixa etária e região, no período de 1999 a 2006.

Métodos: trata-se de um estudo ecológico misto das tendências das três principais causas de ICSAP em menores de vinte anos. Os dados secundários foram provenientes do Sistema de Informação Hospitalar (SIH-SUS) e do censo demográfico do ano de 2001 e projeções populacionais do Instituto Brasileiro de Geografia e Estatistica (IBGE).

Resultados: as três principais causas de ICSAP, em menores de 20 anos, foram as gastroenterites, asma e as pneumonias bacterianas. Houve redução das taxas de internação por gastroenterites (-12,0\%) e asma $(-31,8 \%)$ e, incremento de $142,5 \%$ nas taxas de internações por pneumonias bacterianas, tendências que ocorreram de forma distinta por faixa etária e região.

Conclusões: a descrição das tendências temporais revelou mudanças positivas na evolução das taxas de internações por asma e gastroenterites infecciosas e negativas nas internações por pneumonia. Uma vez que estes problemas de saúde constituem objeto de intervenção prioritária na atenção primária, tais achados evidenciam a necessidade de se aprofundar a análise e reflexão sobre os determinantes do perfil das internações hospitalares no país. Palavras-chave Atenção primária à saúde, Gastroenterite, Asma, Pneumonia 


\section{Introdução}

Em todo mundo, diversos autores têm usado indicadores da atividade hospitalar como medida da efetividade da atenção primária à saúde. $\mathrm{O}$ conceito de problemas de saúde sensíveis aos cuidados ambulatoriais teve origem nos Estados Unidos no início da década de 1990, com os indicadores "ambulatory care sensitive conditions" e "avoidable hospitalizations", 1 e a proporção de internações hospitalares por condições sensíveis tem sido utilizado como marcador de resultado da qualidade dos cuidados primários de saúde 2 e como indicador de acesso ao cuidado ambulatorial. 3,4

O indicador internações por condições sensíveis à atenção primária tem sido abordado por diferentes perspectivas. Na Europa, observa-se uma preocupação dos autores em relação à correta composição da lista de morbidades sensíveis à atenção primária e a validação dessa lista.2,5,6 Nos Estados Unidos, os estudos são direcionados a comparações entre usuários portadores de seguros de saúde e os não portadores de seguro saúde, ao tipo de seguro saúde, ao custo destas internações para os seguros saúde, a análise por gênero e etnia e o efeito dos serviços de saúde de atenção primária nas internações potencialmente evitáveis. 7-12

No Brasil, foi formulado o indicador composto Internações por Condições Sensíveis à Atenção Primária (ICSAP) a partir de uma lista de problemas de saúde para os quais ações efetivas no nível da atenção primária, tais como prevenção de doenças, diagnóstico e tratamento precoce de patologias agudas e o controle e acompanhamento de patologias crônicas, diminuiria o risco de internações. ${ }^{13}$

Estudos recentes têm analisado os fatores que estariam associados a um maior risco de hospitalização por condição sensível à atenção primária, avaliando os efeitos do modelo de atenção primária à saúde e, no Brasil, da Estratégia Saúde da Família (ESF). 14-17 Entre os fatores analisados destacam-se: ocorrência de internação prévia, visitas regulares às unidades de saúde, atenção à saúde não realizada por uma equipe de saúde da família, internação solicitada por médicos que não atuam na equipe de saúde da família, 14 disponibilidade de leitos hospitalares, acesso e qualidade da atenção primária, residir em áreas cobertas pela ESF e tempo de funcionamento da unidade de saúde. ${ }^{17}$

Como os esforços têm se concentrado em estudos que utilizam indicadores compostos, a partir da definição de um conjunto de enfermidades sensíveis à atenção primária, há uma carência de estudos que abordem os principais diagnósticos sensíveis à atenção primária de forma detalhada. Abordar especificamente alguns problemas de saúde que são responsáveis por um grande contingente de internações permite avaliar os efeitos da atenção primária à saúde sobre determinadas situações, direcionando as intervenções que possam qualificar o cuidado neste nível de atenção. Este estudo tem como objetivo analisar as tendências e padrões das principais causas de internações hospitalares por condições sensíveis à atenção primária no Brasil, por faixa etária e região.

\section{Métodos}

Este estudo faz parte do projeto intitulado “Avaliação do impacto da estratégia saúde da família nas internações hospitalares por condições sensíveis à atenção primária no período de 1999 a 2006 em menores de 20 anos no Brasil”.

Trata-se de um estudo ecológico misto das tendências e padrões das três principais causas de ICSAP em indivíduos menores de vinte anos, por área geográfica, no período de janeiro de 1999 a dezembro de 2006, que tem como unidades de análise o Brasil e as cinco regiões. A escolha desse período calendário considerou que o ano de 1999 representou o marco inicial do período de expansão, em nível nacional, da estratégia saúde da família, implantada em 1994.

Os dados demográficos da distribuição por idade da população residente em cada área geográfica considerada na análise para o cálculo de indicadores, foram obtidos no DATASUS (www.datasus.gov.br).

Os dados referentes às internações hospitalares foram provenientes do Sistema de Informação Hospitalar (SIH/SUS), que foi concebido em 1991 como sistema de pagamento das internações realizadas em todos os hospitais vinculados ao Sistema Único de Saúde (SUS), cobrindo cerca de 70\% das internações realizadas no país. Neste estudo foram excluídas as Autorizações de Internação Hospitalar (AIH) de longa permanência, pois essas cumprem, principalmente, propósitos contábeis ou administrativos.

As causas de internações por condições sensíveis à atenção primária foram definidas a partir da lista brasileira para a classificação de causas/condições de internação hospitalar (Portaria 221/MS de 17 de abril de 2008). ${ }^{13}$ Para a identificação de ICSAP, as enfermidades que compõem a lista foram ordenadas, segundo a ocorrência, a partir do número de internações registradas no SIH/SUS e, em seguida, identificadas as três causas mais comuns de internações. As condições mais frequentes de internação foram categorizadas por região (Norte, Nordeste, Sul, 
Sudeste e Centro-Oeste) e por faixa etária ( 0 a 27 dias, 28 dias a 11 meses, menores de 1 ano, 1 a 4 anos, 5 a 9 anos, 10 a 14 anos, 15 a 19 anos e menores de 20 anos).

A taxa de internação foi definida como a razão entre o número de internações hospitalares por condição sensível à atenção primária específica e a população por faixa etária, área e ano, sendo estimada para 10.000 habitantes.

A variação percentual foi calculada como a razão entre a diferença das taxas de internações (do primeiro e último ano analisado) e a taxa de internação do primeiro ano (1999).

O percentual da taxa das três principais causas de ICSAP sobre a taxa de ICSAP, Brasil e regiões, foi calculada como a razão entre as taxas das três principais causas de ICSAP sobre a taxa de ICSAP e expressa em porcentagem.

As taxas de internações hospitalares foram padronizadas por idade para cada unidade de análise (região e país). A padronização das taxas foi realizada pelo método direto, utilizando a população padrão Brasil 2000 (IBGE).

Foram construídas séries históricas para o período do estudo. Inicialmente, foi gerado um banco de dados a partir da base do SIH/SUS. Os dados foram processados e analisados com a utilização dos aplicativos informatizados TABWIN/ Datasus/MS e Microsoft Excel®.

Foram realizadas análises tabular e gráfica comparativa para o estudo das tendências de internações, da evolução das taxas de internações, variação percentual e proporção das internações.

A análise dos dados permitiu a descrição da situação nacional e regional, considerando-se as internações hospitalares em menores de 20 anos no período analisado.

\section{Resultados}

Em menores de vinte anos, no Brasil, a primeira causa de internação foram as gastroenterites infecciosas e complicações $(60,5$ internações por $10 \mathrm{mil} \mathrm{em}$ 1999 e 53,3 por 10 mil em 2006), a segunda, asma (33,1 por 10 mil em 1999 e 22,6 por 10 mil em 2006) e a terceira, as pneumonias bacterianas (7,4 internações por 10 mil em 1999 e 18,0 por 10 mil em 2006). No período considerado, houve redução das taxas de internação por gastroenterites infecciosas e complicações $(-12,0 \%)$ e asma $(-31,8 \%)$. Entretanto, houve um incremento de $142,5 \%$ nas taxas de internações por pneumonias bacterianas, sendo mais expressivo entre os anos 2001 e 2002 (Tabelas 1 e 2).

Tabela 1

Ordenamento das principais causas de ICSAP, por faixa etária. Brasil, 1999 a 2006.

\begin{tabular}{|c|c|}
\hline Faixa etária & Três principais causas de ICSAP \\
\hline 0 a 27 dias & $\begin{array}{l}1^{\circ} \text { Gastroenterites infecciosas e complicações } \\
2^{\circ} \text { Doenças relacionadas ao pré-natal e parto } \\
3^{\circ} \text { Pneumonias bacterianas }\end{array}$ \\
\hline 28 dias a 11 meses & $\begin{array}{l}1^{\circ} \text { Gastroenterites infecciosas e complicações } \\
2^{\circ} \text { Pneumonias bacterianas } \\
3^{\circ} \text { Asma }\end{array}$ \\
\hline Menores de 1 ano & $\begin{array}{l}1^{\circ} \text { Gastroenterites infecciosas e complicações } \\
2^{\circ} \text { Pneumonias bacterianas } \\
3^{\circ} \text { Asma }\end{array}$ \\
\hline 1 a 4 anos & $\begin{array}{l}1^{\circ} \text { Gastroenterites infecciosas e complicações } \\
2^{\circ} \text { Asma } \\
3^{\circ} \text { Pneumonias bacterianas }\end{array}$ \\
\hline 5 a 9 anos & $\begin{array}{l}1^{\circ} \text { Gastroenterites infecciosas e complicações } \\
2^{\circ} \text { Asma } \\
3^{\circ} \text { Pneumonias bacterianas }\end{array}$ \\
\hline 10 a 14 anos & $\begin{array}{l}1^{\circ} \text { Gastroenterites infecciosas e complicações } \\
2^{\circ} \text { Asma } \\
3^{\circ} \text { Infecção no rim e trato urinário }\end{array}$ \\
\hline 15 a 19 anos & $\begin{array}{l}1^{\circ} \mathrm{Gastroenterites} \mathrm{infecciosas} \mathrm{e} \mathrm{complicações} \\
2^{\circ} \text { Infecção no rim e trato urinário } \\
3^{\circ} \text { Asma }\end{array}$ \\
\hline $\begin{array}{l}\text { Menores de } 20 \\
\text { anos }\end{array}$ & $\begin{array}{l}1^{\circ} \text { Gastroenterites infecciosas e complicações } \\
2^{\circ} \text { Asma } \\
3^{\circ} \text { Pneumonias bacterianas }\end{array}$ \\
\hline
\end{tabular}

ICSAP= internação hospitalar por condições sensíveis à atenção primária. Fonte: SIH-SUS/MS, dados populacionais do IBGE/DATASUS/MS. 
Tabela 2

Evolução das taxas de internação das principais causas de ICSAP e variação percentual, por faixa etária. Brasil, 1999 a 2006.

\begin{tabular}{|c|c|c|c|c|c|c|c|c|c|c|}
\hline \multirow{2}{*}{$\begin{array}{l}\text { Faixa } \\
\text { Etária }\end{array}$} & \multirow{2}{*}{$\begin{array}{l}\text { Três principais causas de } \\
\text { ICSAP }\end{array}$} & \multicolumn{8}{|c|}{ Evolução da Taxa de Internação } & \multirow{2}{*}{$\begin{array}{c}\text { V \% } \\
1999- \\
2006\end{array}$} \\
\hline & & 1999 & 2000 & 2001 & 2002 & 2003 & 2004 & 2005 & 2006 & \\
\hline \multirow{3}{*}{$\begin{array}{l}\text { Menores } \\
\text { de } 1 \text { ano }\end{array}$} & Gastroenterites infecciosas e complicações & 444,0 & 417,8 & 400,1 & 380,4 & 356,6 & 318,6 & 298,9 & 267,2 & $-39,8$ \\
\hline & Pneumonias bacterianas & 56,6 & 39,0 & 30,6 & 127,6 & 167,8 & 154,2 & 131,4 & 129,0 & 128,0 \\
\hline & Asma & 95,8 & 104,6 & 96,9 & 107,9 & 106,1 & 98,1 & 82,7 & 75,8 & $-20,9$ \\
\hline \multirow{3}{*}{$\begin{array}{l}1 \text { a } 4 \\
\text { anos }\end{array}$} & Gastroenterites infecciosas e complicações & 130,5 & 125,1 & 135,9 & 140,5 & 139,0 & 128,7 & 128,1 & 130,7 & 0,1 \\
\hline & Asma & 87,8 & 92,6 & 85,7 & 87,8 & 78,7 & 72,3 & 64,0 & 56,8 & $-35,2$ \\
\hline & Pneumonias bacterianas & 14,7 & 12,1 & 10,6 & 40,8 & 52,3 & 48,1 & 42,6 & 42,8 & 192,3 \\
\hline \multirow{3}{*}{$\begin{array}{l}5 \text { a } 9 \\
\text { anos }\end{array}$} & Gastroenterites infecciosas e complicações & 29,2 & 29,8 & 32,2 & 35,0 & 34,2 & 30,8 & 32,0 & 34,6 & 18,5 \\
\hline & Asma & 25,2 & 28,1 & 26,3 & 27,9 & 24,8 & 22,8 & 22,1 & 20,2 & $-20,1$ \\
\hline & Pneumonias bacterianas & 2,5 & 2,5 & 2,4 & 7,9 & 9,3 & 9,0 & 8,4 & 9,0 & 252,1 \\
\hline \multirow{3}{*}{$\begin{array}{l}10 \text { a } 14 \\
\text { anos }\end{array}$} & Gastroenterites infecciosas e complicações & 15,3 & 15,7 & 16,3 & 17,6 & 16,5 & 14,4 & 14,9 & 15,7 & 2,7 \\
\hline & Asma & 11,7 & 12,7 & 11,5 & 11,8 & 10,1 & 9,4 & 8,2 & 7,7 & $-34,2$ \\
\hline & Infecção no rim e trato urinário & 4,40 & 4,36 & 4,48 & 4,22 & 4,31 & 4,29 & 4,25 & 4,44 & 0,9 \\
\hline \multirow{3}{*}{$\begin{array}{l}15 \text { a } 19 \\
\text { anos }\end{array}$} & Gastroenterites infecciosas e complicações & 13,1 & 12,1 & 12,5 & 13,4 & 13,0 & 11,1 & 11,4 & 11,7 & $-10,8$ \\
\hline & Infecção no rim e trato urinário & 10,1 & 9,9 & 10,6 & 10,8 & 11,1 & 11,4 & 11,4 & 11,0 & 8,9 \\
\hline & Asma & 9,9 & 9,3 & 8,1 & 7,8 & 6,8 & 6,3 & 5,0 & 4,6 & $-53,1$ \\
\hline \multirow{3}{*}{$\begin{array}{l}\text { Menores } \\
\text { de } 20 \\
\text { anos }\end{array}$} & Gastroenterites infecciosas e complicações & 60,5 & 58,2 & 60,3 & 61,5 & 59,5 & 53,9 & 53,3 & 53,3 & $-12,0$ \\
\hline & Asma & 33,1 & 35,3 & 32,5 & 33,8 & 30,6 & 28,1 & 25,0 & 22,6 & $-31,8$ \\
\hline & Pneumonias bacterianas & 7,4 & 6,0 & 5,2 & 17,4 & 22,0 & 20,5 & 17,8 & 18,0 & 142,5 \\
\hline
\end{tabular}

ICSAP= internação hospitalar por condições sensíveis à atenção primária.

Fonte: SIH-SUS/MS, dados populacionais do IBGE/DATASUS/MS

Observou-se que as gastroenterites infecciosas e complicações foram a primeira causa de internação em todas as faixas etárias consideradas, mas houve variação quanto a segunda e terceira causas entre asma, pneumonias bacterianas, infecção no rim e trato urinário e doenças relacionadas ao parto e prénatal (Tabela 1).

Nas faixas etárias de menores de 1 ano, 1 a 4 anos e 5 a 9 anos, as três principais causas de internação foram gastroenterites infecciosas e complicações, asma e pneumonias bacterianas, e, nas faixas de 10 a 14 anos e de 15 a 19 anos, gastroenterites infecciosas e complicações, infecção no rim e trato urinário e asma. Ressalta-se que, na faixa etária de 0 a 27 dias, as doenças relacionadas ao pré-natal e parto foram registradas como a segunda principal causa de internação hospitalar (Tabela 1).

As pneumonias bacterianas foram a segunda causa de internação entre os menores de um ano e configuraram-se como a terceira causa de internação nas seguintes faixas etárias: 0 a 27 dias, 1 a 4 anos, 5 a 9 anos (Tabela 1). É válido ressaltar que houve um incremento das taxas de internação por pneumonias bacterianas em todas as faixas etárias, a exceção dos indivíduos pertencentes à faixa etária de 15 a 19 anos (Tabela 1).

As internações por gastroenterites infecciosas e complicações em menores de vinte anos corresponderam a $45,2 \%$ de todas as ICSAP, em 1999, e $44,2 \%$, em 2006 (Figura 1). A magnitude das taxas de internações por essa causa é especialmente elevada nos menores de um ano, chegando mesmo nos três primeiros anos do período analisado a exceder os valores observados por todas as demais causas de ICSAP, alcançando patamares superiores a 400,0 internações por 10.000 mil (Figura 1), com redução percentual $(-39,8 \%)$ entre o início e o final do período (Tabela 2 ).

Nas cinco regiões brasileiras, em todo o período, verificou-se que as gastroenterites infecciosas e complicações, asma e pneumonias bacterianas mantiveram-se como as três principais causas de internação por ICSAP, em menores de 20 anos (Figuras 2-4).

Em relação à primeira causa de internação, as gastroenterites infecciosas e complicações, maiores 
Evolução das taxas de internação por gastroenterites infecciosas e complicações, ICSAP exceto gastroenterites infecciosas e complicações, e por demais causas, por 10.000 , nas faixas etárias menores de um ano e menores de 20 anos, Brasil, 1999-2006.

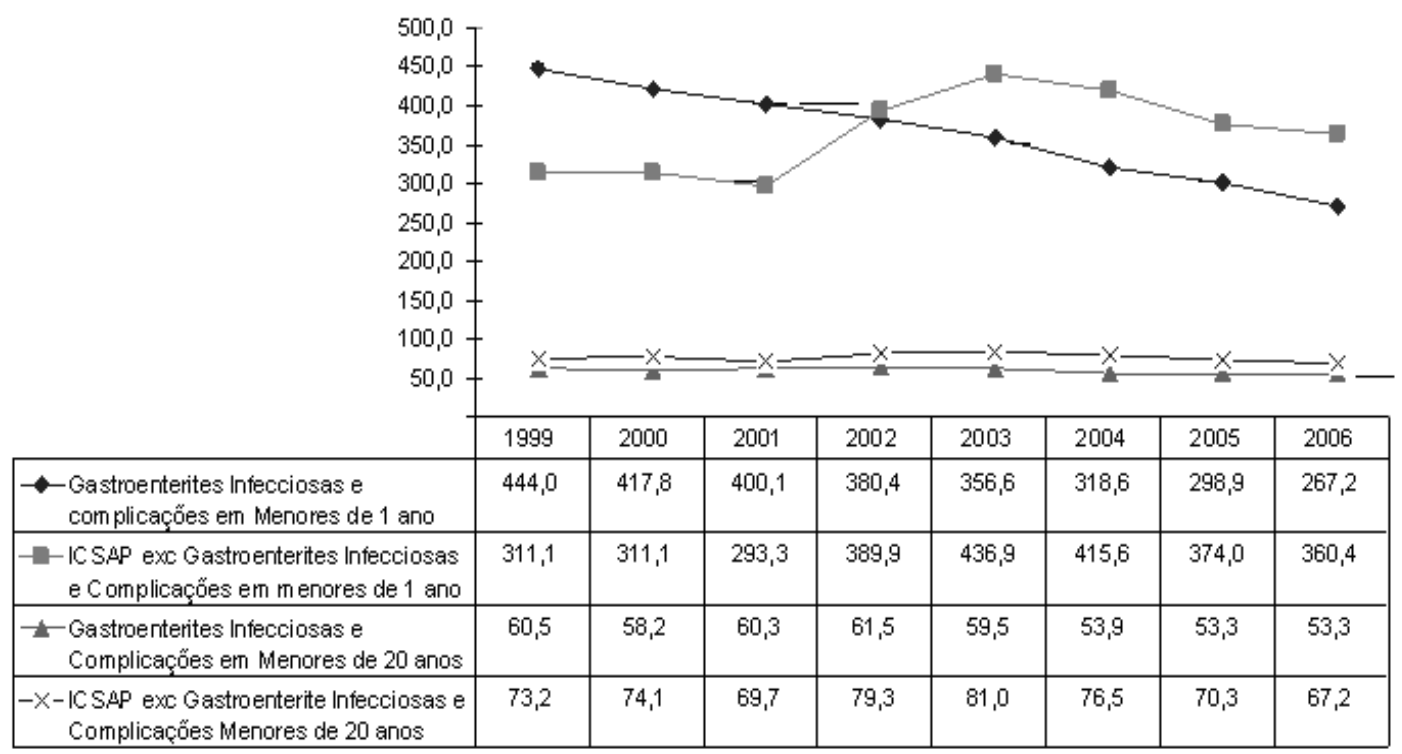

Gastroenterites infecciosas e complicações: internação hospitalar por gastroenterites infecciosas e complicações infecciosas;

ICSAP exc gastroenterites infecciosas e complicações: internação hospitalar por condições sensíveis à atenção primária excluindo-se as internações pelo grupo das gastroenterites infecciosas e complicações:

Demais causas exc partos: demais internações hospitalares excluindo-se partos:

Fonte de Dados: SIH-SUS/MS, dados populacionais do IBGE/DATASUS/MS.

Figura 2

Evolução das taxas de internação por gastroenterite por 10.000 habitantes em menores de 20 anos, por região geográfica. Brasil, 1999-2006.

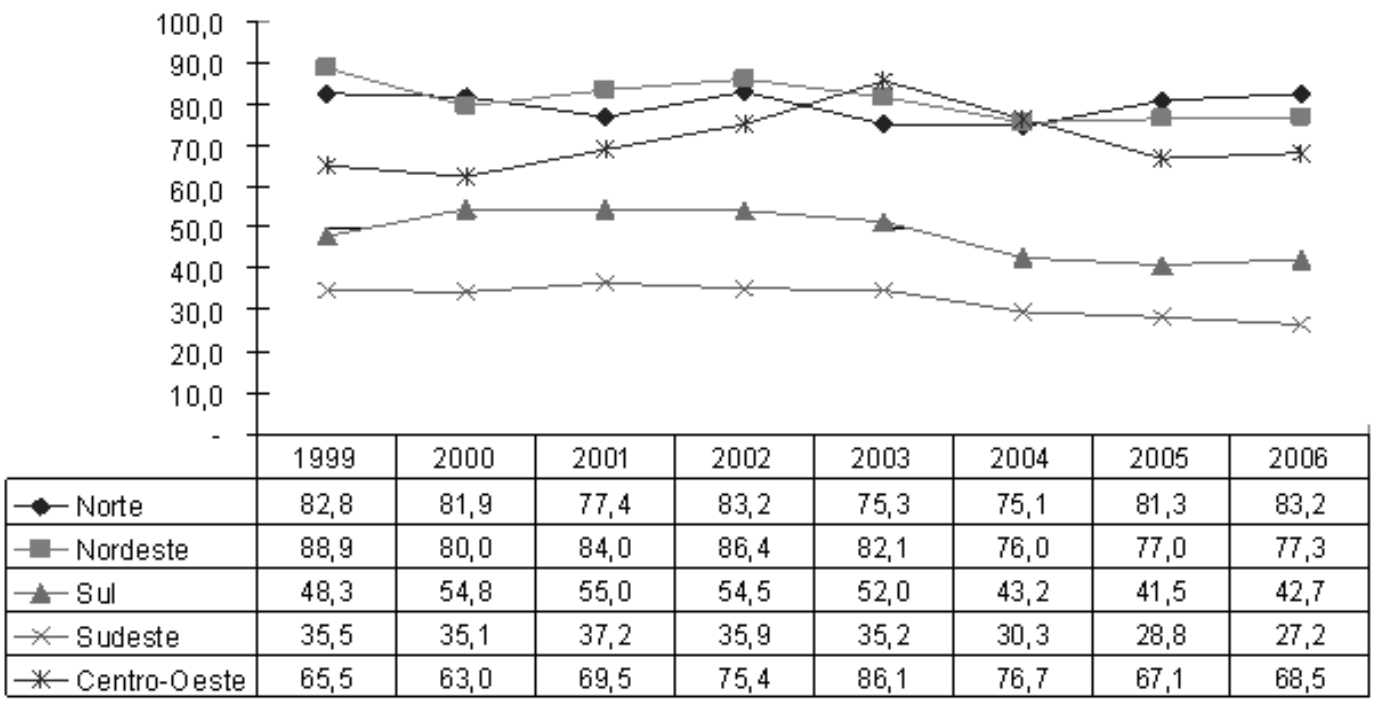

Fonte: SIH-SUS/MS, dados populacionais do IBGE/DATASUS/MS. 


\section{Figura 3}

Evolução das taxas de internação por pneumonia bacteriana por 10.000 habitantes em menores de 20 anos, por região geográfica. Brasil, 1999-2006.

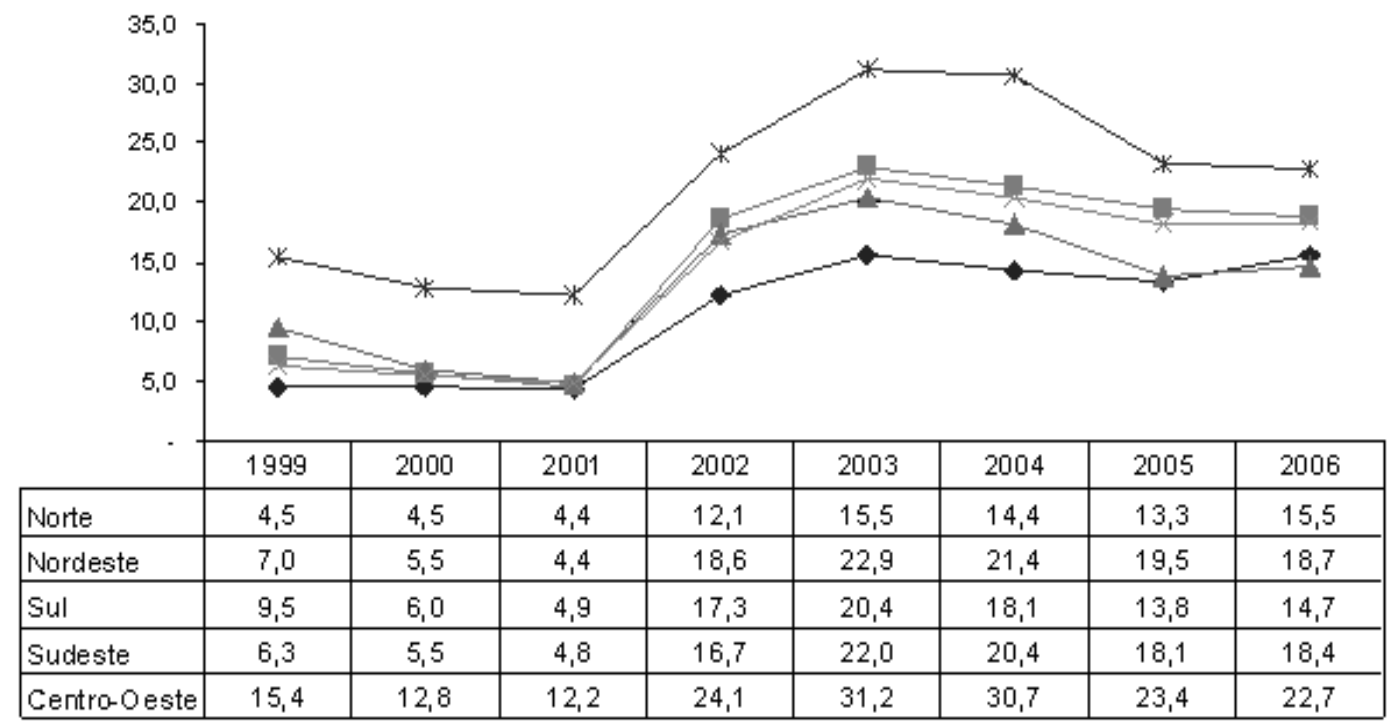

Fonte: SIH-SUS/MS, dados populacionais do IBGE/DATASUS/MS

\section{Figura 4}

Evolução das taxas de internação por asma por 10.000 habitantes em menores de 20 anos, por região geográfica. Brasil, 1999-2006.

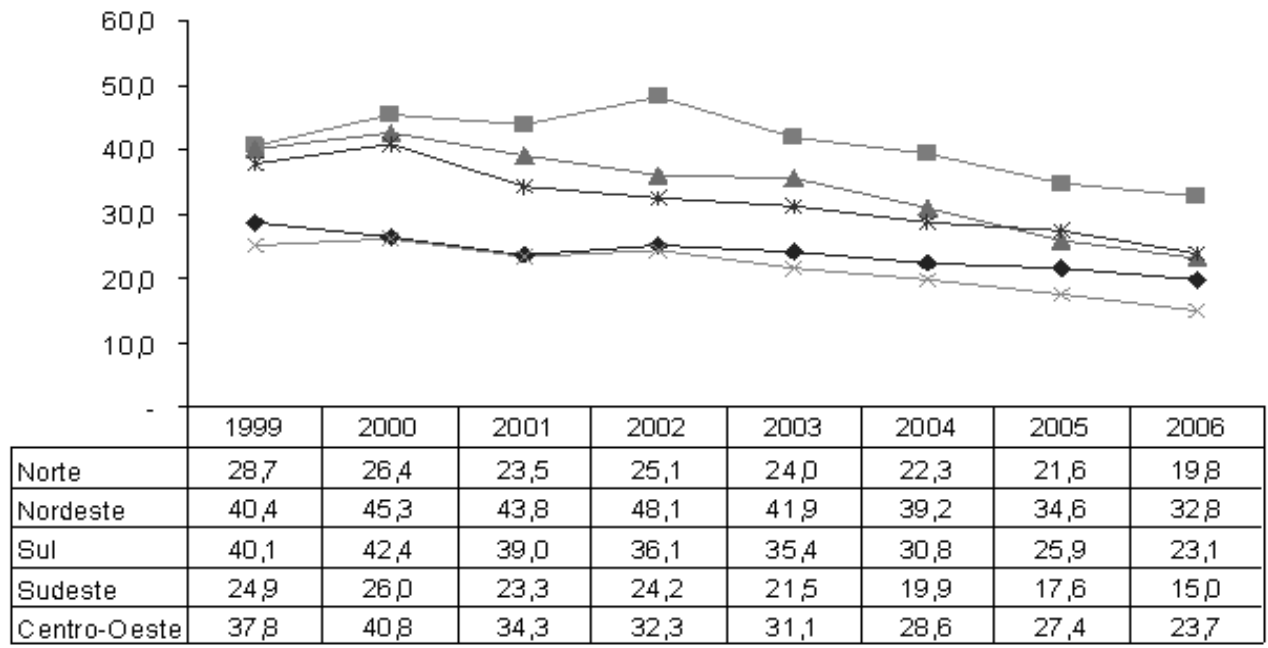

Fonte: SIH-SUS/MS, dados populacionais do IBGE/DATASUS/MS. 
taxas por 10.000 mil foram observadas nas regiões Nordeste (88,9 em 1999 e 77,3 em 2006) e Norte (82,8 em 1999 e 83,2 em 2006). Foram observadas reduções nas taxas de internação por gastroenterites infecciosas e complicações nas regiões Sudeste $(-23,5 \%)$, Nordeste $(-13,1 \%)$ e Sul $(-11,5 \%)$ e incremento das taxas nas regiões Centro-Oeste $(4,6 \%)$ e Norte $(0,4 \%)$,como se observa na Figura 2.

Usando a Região Sudeste como referência e considerando os pontos extremos do período, observou-se aumento das razões de taxas entre as regiões. As variações nas razões de taxas entre 1999 e 2006 foram de, respectivamente, 1,8 para 2,5 nas razões entre as Regiões Centro-Oeste e Sudeste, de 2,3 para 3,0 nas razões entre Norte e Sudeste e de 2,5 para 2,8 nas razões entre Nordeste e Sudeste (Figura 2).

Quanto à pneumonia, todas as regiões apresentaram aumento das taxas de internação de maneira expressiva a partir do ano de 2001. Comparando o início e o final do período, observou-se incremento em todas as regiões, mais expressivo nas regiões Norte $(246,6 \%)$, Sudeste $(193,3 \%)$ e Nordeste $(166,9 \%)$ e menor nas regiões Sul $(54,5 \%)$ e CentroOeste $(48,0 \%)$ (Figura 3 ).

$\mathrm{Na}$ análise das taxas de internação por asma observou-se tendência à redução superiores a 30\% em quase todas as regiões, a exceção da Região Nordeste, onde a redução na taxa de internação hospitalar por asma foi de $19 \%$.

\section{Discussão}

No Brasil, no período de 1999 a 2006, as três principais causas de internação por condições sensíveis à atenção primária, em menores de 20 anos, foram as gastroenterites e suas complicações, asma e as pneumonias bacterianas que, em conjunto, representaram $75,5 \%$ do total de ICSAP em 1999 e 78,0\% em 2006 Os resultados apontaram para uma tendência à redução nas taxas de hospitalizações por essas causas, que ocorreu de forma distinta por faixa etária, região e causa de internação.

As distintas reduções nas taxas de internações pelas causas analisadas podem estar associadas a uma grande variedade de fatores. Destacam-se os relacionados ao perfil sócio-demográfico e econômico das populações (como renda per capita, esgotamento sanitário, nível educacional, entre outros), a situações epidemiológicas específicas (maior prevalência ou incidência de determinados agravos), à própria rede de serviços existentes em determinada região e às ações específicas da prestação do cuidado primário de saúde, em especial, pelos profissionais da estratégia de saúde da família. As Regiões Norte e Nordeste, onde foram observadas as maiores taxas de ICSAP, apresentam o menor produto interno bruto (PIB) per capita, as maiores taxas de analfabetismo, as menores coberturas de esgotamento sanitário e as maiores taxas de mortalidade infantil.

A análise do perfil de morbimortalidade da população brasileira tem mostrado que no país, nos últimos quinze anos, as doenças infecciosas e parasitárias ainda representam cerca de $9 \%$ do total de internações, sendo estes valores superiores nas regiões Norte e Nordeste e, do conjunto de internações desse grupo, as doenças infecciosas intestinais representam a maior parcela. 18

A elevada representatividade das internações por gastroenterites infecciosas e complicações nas populações residentes em regiões onde há maior concentração de pobreza é um achado constante em estudos realizados no país 19 e, é sabido que precárias condições socioeconômicas aumentam o risco de diarréia, principalmente quando associadas à falta de saneamento básico e a deficientes condições de vida. 19,20 Neste estudo, as internações por gastroenterites infecciosas e complicações foram, entre as condições estudadas, as que apresentaram os maiores valores de taxa de internação independente da faixa etária analisada, com destaque para as taxas na Região Norte, Nordeste e Centro-Oeste. Destacase que, embora tenha havido uma redução das taxas de internações analisadas, esta evolução ocorreu de forma desigual entre as regiões brasileiras, ampliando-se as desigualdades já existentes.

Apesar da tendência à redução nas taxas de internações e mortalidade por gastroenterites infecciosas e complicações, e da existência de medidas terapêuticas efetivas e de baixa complexidade (reidratação oral e a antibioticoterapia associada), ${ }^{19}$ as gastroenterites ainda possuem alta representatividade no perfil de morbidade da população brasileira, sobretudo para as faixas etárias menores de cinco anos.

A existência de fatores de risco para a diarreia que ultrapassam os limites dos serviços assistenciais e a longa persistência dessa morbidade no perfil de saúde da população brasileira remete à necessidade de políticas públicas de saneamento básico na redução do impacto da pobreza sobre a diarreia, ${ }^{20}$ além da necessidade de expandir a rede assistencial de ações da atenção primária à saúde.

Vale ressaltar o comportamento das internações por pneumonias bacterianas no Brasil e regiões, que apresentaram uma tendência ao aumento, diferentemente das internações por gastroenterites infecciosas e complicações e asma. Diante da expansão da 
estratégia de saúde da família como modelo de atenção primária, seria esperado que as taxas de internação dessas três patologias apresentassem tendências de redução semelhantes. A literatura científica identifica como fatores de riscos associados ao desenvolvimento de pneumonias bacterianas na infância a pouca idade materna, baixo peso ao nascer, ausência de aleitamento materno e história de pneumonia anterior, 21,22 porém esses fatores de risco são insuficientes para explicar os achados deste estudo, tornando-se evidente a necessidade de aprofundamento de algumas questões através de estudos analíticos, que permitam identificar fatores explicativos das tendências ao aumento desta taxa. É válido ressaltar que a expansão da ESF ampliou o acesso à atenção à saúde através da ampliação do acesso à atenção primária, o que por consequência pode ter aumentado a chance de identificação e referência dos casos necessários à internação.

Em relação à asma, apesar de sua prevalência variar muito entre os países no mundo, de um modo geral, tem sido descrita tendência ao aumento da sua incidência nas últimas três décadas, 22 com elevadas taxas de prevalência (15 a 20\%) nos Estados Unidos, Brasil, Canadá, Austrália, Nova Zelândia e outros países desenvolvidos.22,23 No presente trabalho, apesar de elevadas taxas de internação por asma, principalmente nas faixas etárias menores de um ano e de um a quatro anos, observou-se uma tendência à redução nas internações hospitalares por esta causa, ao longo da série histórica, em todas as unidades de análise estudadas, apresentando a população de 15 a 19 anos a maior redução percentual e a Região Sudeste as menores taxas de internação.

A interação genética, tabagismo materno, dieta, estresse, uso de antibióticos, parto cesariana, aleitamento materno, exposição a animais, tamanho e estrutura familiar, situação socioeconômica são fatores de risco associados ao desenvolvimento da asma. ${ }^{24}$ Mesmo com os diversos fatores de risco abordados pela literatura como relacionados à asma, ainda não se tem clareza quanto ao fundamental mecanismo imunológico, genético e ambiental subjacentes ao desenvolvimento desse estado e sua maior expressão, especialmente no mundo desenvolvido.

Por outro lado, independente da falta de clareza dos mecanismos biológicos e ambientas que desencadeiam a doença, é possível identificar fatores de risco associados a este problema, passíveis de serem abordados por ações da atenção primária, tais como: identificação dos pacientes portadores da morbidade e assistência adequada a estes, expansão da atenção ao pré-natal com incentivo ao aleitamento materno e ao parto natural, aconselhamento nutricional, entre outras. É possível que o incremento de tais ações no âmbito da atenção primária em saúde, nos últimos anos, tenha sido responsável ao menos por parcela da redução das internações hospitalares relacionadas a este problema de saúde. Assim, mudanças positivas na evolução das taxas de internações por asma e, também, por gastroenterites infecciosas e complicações, podem estar associadas à maior cobertura e melhoria da atenção à saúde, especialmente após a implantação e expansão da ESF no país.

Apesar de revelar informações relevantes sobre as causas de ICSAP mais frequentes, os dados deste estudo apresentam algumas limitações, requerendo cautela na sua utilização. Em primeiro lugar, vale ressaltar que se trata de um estudo descritivo baseado em dados secundários disponibilizados pelos sistemas nacionais de informação em saúde e, nesse sentido, sujeitos aos possíveis vieses relacionados à qualidade dos dados disponíveis. Todavia, verifica-se, ao longo do tempo, um avanço dos sistemas nacionais de informação em saúde, observando-se grande disponibilidade e melhoria da qualidade das informações geradas, o que pode produzir, em determinado momento da série histórica, aumento em algumas taxas de internações por melhoria no registro e melhor definição do diagnóstico da morbidade, o que pode ter ocorrido de forma diferenciada entre as regiões. Ademais, o cálculo de taxas de internação por habitante depende de dados populacionais que, para o período estudado, são objeto de projeções e estimativas (com exceção dos dados da população recenseada em 2001) e, portanto, sujeitas a desvios de cálculo.

Esses e outros aspectos da qualidade dos dados não invalidam a importância e utilização das informações geradas, especialmente considerando-se que estas têm potencial decisivo de promover a melhoria da qualidade da informação futuramente prestada, na medida em que se cumpra o objetivo de devolvê-las amplamente ao conjunto de gestores e profissionais do SUS, implicados com a produção e gestão das informações em saúde.

A descrição das tendências temporais revelou mudanças positivas na evolução das taxas de internações por asma e gastroenterites infecciosas e complicações e negativas nas internações por pneumonia bacterianas. Uma vez que esses problemas de saúde constituem objeto de intervenção prioritária na atenção primária, tais achados evidenciam a necessidade de se aprofundar a análise e reflexão sobre os determinantes do perfil das internações hospitalares no Brasil. 


\section{Agradecimentos}

Os autores agradecem ao Departamento de Atenção Básica do Ministério da Saúde, que viabilizou a rea-

\section{Referências}

1. Billings J, Zeitel L, Lukomnic J, Carey TS, Blank AE, Newman L. Impact of socioeconomic status on hospital use in New York City. Health Affairs. 1993;12: 162-73.

2. Caminal HJ, Morales EM, Sanchez RE, Cubells LMJ Bustins PM. Hospitalizations preventable by timely and effective primary health care. Aten Primaria. 2003; 31(1): 2003 Jan; 6-14; discussion 16-7.

3. Caminal J, Starfield B, Sanchez E, Casanova C, Morales M The role of primary care in preventing ambulatory care sensitive conditions. Eur J Public Health. 2004; 14: 246-51.

4. Ansari Z, Laditka, JN, Laditka SB. Access to health care and hospitalization for ambulatory care sensitive conditions. Med Care Res Rev. 2006; 63: 719-41.

5. Caminal HJ, Sánchez E, Morales M, Peiró R, Márquez S. Avances en España en la investigación con el indicador hospitalización por enfermedades sensibles a cuidados de atención primaria. Rev Esp Salud Pública. 2002; 76: 18996.

6. Purdy S, Griffin T, Salisbury C, Sharp D. Ambulatory care sensitive conditions: terminology and disease coding need to be more specific to aid policy makers and clinicians. Public Health. 2009; 123: 169-73.

7. Probst JC, Laditka JN, Laditka SB. Association between community health center and rural health clinic presence and county-level hospitalization rates for ambulatory care sensitive conditions: an analysis across eight US states. BMC Health Serv Res. 2009; 9: 134.

8. Kronman AC, Ash AS, Freund KM, Hanchate A, Emanuel EJ. Can primary care visits reduce hospital utilization among medicare beneficiaries at the end of life? J Gen Intern Med. 2008; 23: 1330-5.

9. Bindman AB, Chattopadhyay A, Osmond DH, Huen W, Bacchetti $P$. The impact of medicaid managed care on hospitalizations for ambulatory care sensitive conditions. Health Serv Res. 2005; 40: 1.

10. Hossain MM, Laditka JN. Using hospitalization for ambulatory care sensitive conditions to measure access to primary health care: an application of spatial structural equation modeling. Int J Health Geogr. 2009; 8: 51.

11. Laditka JN, Laditka SB. Insurance status and access to primary health care: disparate outcomes for potentially preventable hospitalization. J Health Soc Policy. 2004; 19: 81-100

12. Bindman AB, Chattopadhyay A, Auerback GM Interruptions in medicaid coverage and risk for hospitalization for ambulatory care-sensitive conditions. Ann Intern Med. 2008; 149: 854-60.

13. Alfradique ME, Bonolo PF, Dourado I, Lima-Costa MF, Macinko J, Mendonça CS, Oliveira VB, Sampaio LFR, De

Recebido em 5 de abril de 2010

Versão final apresentada em 30 de agosto de 2010

Aprovado em 1 de outubro de 2010 lização do estudo, desde a concepção teórica ao incentivo financeiro, apoiando o debate sobre o tema.

Simoni C, Turci MA. Lista brasileira de internações por condições sensíveis à atenção primária: uma nova ferramenta para medir o desempenho do serviço de saúde. Cad Saúde Pública. 2009; 25: 1337-49.

14. Fernandes VBL, Caldeira AP, Faria AA, Neto JFR. Internações sensíveis na atenção primária como indicador de avaliação da Estratégia Saúde da Família. Rev Saúde Pública. 2009; 43: 928-36.

15. Marquez-Calderon S, Rodriguez del Aguila MM, PereaMilla E, Ortiz J, Bermudez-Tamayo C. Factors associated with hospitalization for ambulatory care sensitive conditions in municipalities. Gac Sanit. 2003; 17: 360-7.

16. Magan P, Otero A, Alberquilla A. Geographic variations in avoidable hospitalizations in the elderly, in a health system with universal coverage Jose Manuel Ribera. BMC Health Serv Res. 2008; 8: 42

17. Nedel FB, Facchini LA, Martín-Mateo M, Vieira LA, Thumé E. Family health program and ambulatory caresensitive conditions in Southern Brazil. Rev Saúde Pública. 2008; 42: 1041-52

18. Carmo EH, Barreto ML, Silva Jr JB. Mudanças no padrão de morbimortalidade da população brasileira: os desafios para o novo século. Epidemiol Serv Saúde. 2003; 12: 6375

19. Waldman EA, Barata RCB, Moraes JC, Guibu IA, Timenetsky MCST. Gatroenterites e infecções respiratórias agudas em crianças menores de cinco anos, em área da região Sudeste do Brasil, 1986-1987. Rev Saúde Pública. 1997; 31: 62-70.

20. Genser B, Strina A, Santos LA, Teles CA, Prado MS, Cairncross S, Barreto ML. Impact of a city-wide sanitation intervention in a large urban centre on social, environmental and behavioural determinants of childhood diarrhoea: analysis of two cohort studies. Int J Epidemiol. 2008; 37: $831-40$.

21. Victora CG, Fuchs SC, Flores, JAC, Fonseca W, Kirkwood B. Risk factors for pneumonia among children in a Brazilian metropolitan area. Pediatrics. 1994; 93: 977-85.

22. Nascimento LFC, Marcitelli R, Agostinho FS, Gimenes CS. Análise hierarquizada dos fatores de risco para pneumonia em crianças/ Hierarchical approach to determining risk factors for pneumonia in children. J Bras Pneumol. 2004; 30: $445-51$

23. International Study of Asthma and Allergies in Childhood (ISAAC) Steering Committee. Worldwide variation in prevalence of symptoms of asthma, allergic rhinoconjunctivitis, and atopic eczema: ISAAC. Lancet. 1998; 351: 1225-32.

24. Padmaja S, Piush JM, Malcolm RS. Asthma: epidemiology, etiology and risk factors. Can Med Assoc J. 2009; 181(9). 